\title{
Methods of engineering geophysics in the control of the reclamation state of agricultural land
}

\author{
Abdul-Gapur Kerimov ${ }^{1}$, Anna Saltanova ${ }^{l}$, Levon Mkrtchyan $^{l}$, Olga Zelivyanskaya ${ }^{l}$ and Elizaveta Kerimova ${ }^{l}$ \\ North Caucasus Federal University, 1, Pushkin, Stavropol, 355017, Russia
}

\begin{abstract}
The article provides information about the possibility of monitoring the reclamation situation of agricultural land by studying the soil-lithological profile by means of electrometric methods. The essence of the applied resistance method is the study of the soil layer using constant or variable electric fields. For engineering geophysical works in sand-clay sections typical of the Stavropol Territory, various variants of research technologies are presented. The conducted studies have shown the effectiveness of the electrometric method of vertical electrical sounding, which allows, based on surface observations with a minimum amount of control drilling and analytical work, to obtain operational information about changes in the area and depth of such an important parameter for assessing the reclamation state of soils as their specific electrical resistance, depending on humidity and salinity. The VEZ method, in addition to the available information about waterlogged and saline wetlands observed on the earth's surface by traditional methods, allows us to obtain information about hidden unfavorable zones: about changes in their configuration in area and depth.
\end{abstract}

\section{Introduction}

The main indicator of the reclamation situation that affects the soil-forming processes of artificially irrigated lands is the level of ground water, or rather the depth of its occurrence.

The main condition for the favorable reclamation situation is that the mineralized ground water does not have its depressing effect on the root system of plants. This condition is met if the capillary rim does not reach the root layer during its upward movement from the aquifer, i.e. it does not come into contact with it. In other words, the thickness of the root layer-- $\mathrm{N}_{\mathrm{KC}}$ should not exceed the thickness of the supracapillary-rim layer: $\mathrm{N}_{\mathrm{HKK}}>\mathrm{N}_{\mathrm{KC}}$.

The soil layer consists of an aquifer and an aeration zone; in turn, each of them is divided into separate parts in accordance with the formed value of the gradient of the soil moisture ratio to the depth of the ground water level (UGV). The humidity curve provides basic information about the reclamation environment (Fig. 1). The UGR is determined by the humidity curve - in the figure, this corresponds to the maximum value associated with the upper part (roof) of the aquifer. In turn, the minimum on the moisture curve, marked in the roof of the capillary border, determines the thickness of the supracapillary-border thickness-- $\mathrm{N}_{\mathrm{HKK}}$. It should be noted that in our example, there is no mineralized ground water.
The $\mathrm{N}_{\mathrm{KC}}$ value is known in advance for each of the cultivated crops, the $\mathrm{N}_{\mathrm{HKK}}$ value is determined by the moisture curve. Thus, the moisture curve is the source of the most complete information for assessing the reclamation status of fertile land. To control the reclamation state of agricultural land, the authors propose to use methods of exploration geophysics based on the measurement of the specific electrical resistance (resistivity) of rocks composing the soil layer, since the measured resistivity of rocks mainly depends on the salinity of rocks $\mathrm{C}$ and humidity W. It should be noted that a distinctive feature of electrical exploration is that this type of work has about a hundred different modifications and the measured UES is one of the most informative physical parameters in the study of the earth's interior [1].

According to the authors, the method of resistances will most effectively solve the problems of monitoring the soil-reclamation situation if it is performed in the modification of electric profiling or vertical electric sounding.

\footnotetext{
* Corresponding author: akerimov@ncfu.ru
} 


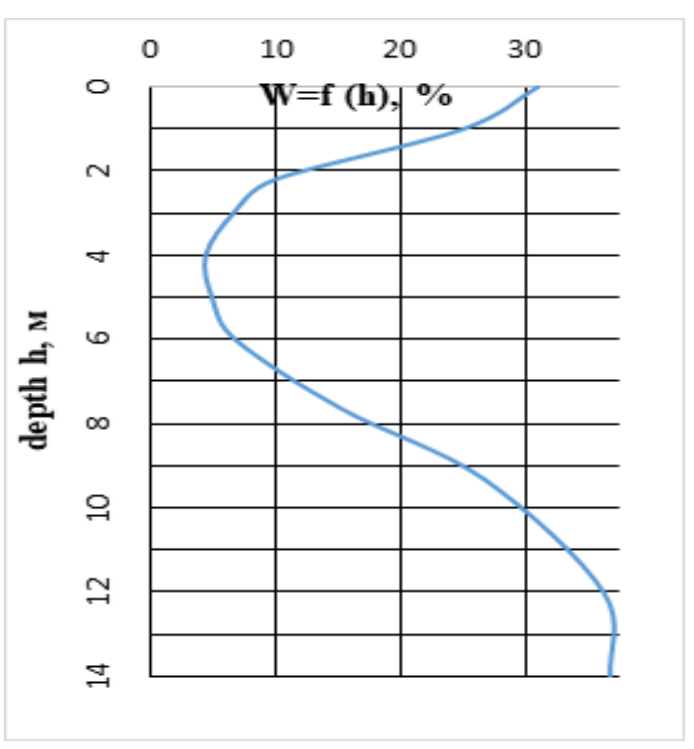

Fig. 1. Scheme of moisture distribution in soils and layerby-layer separation of the soil profile

\section{Materials and Methods}

The method of vertical electric sounding.

The essence of this method of resistances is to study by means of constant or variable electric fields of the soil-lithological layer. Passing through two grounded electrodes A and B, a current of force I, from any source, for example, a current source in the form of a machine generator, we measure the electric field using the other two measuring electrodes $\mathrm{M}$ and $\mathrm{N}$, using a measuring device - a voltmeter.

According to the Ohm's law, the WES $\mathrm{p}$ of a homogeneous medium is calculated by the formula:

$$
\rho=K * \Delta U / I
$$

where $\Delta U$ - the potential difference measured between the measuring electrodes $\mathrm{M}$ and $\mathrm{N}, \mathrm{B}$;

$I$ - current in the current electrode circuit $\mathrm{AB}, \mathrm{mA}$;

$K$ - the probe coefficient, determined by the distance between the electrodes, $\mathrm{m}$.

Depending on the tasks to be solved for monitoring the reclamation state of agricultural land, the installations can be divided into several types, depending on the number of electrodes and their relative position relative to each other: two-point, three-point and fourpoint installations. The most common is a symmetrical four-point AMTV installation (Schlumberger installation). In this installation, the current and measuring electrodes are located on a straight line, symmetrically relative to the current electrodes $A B$, i.e. this installation belongs to a straight line. The distance between the measuring electrodes $\mathrm{M} \mathrm{N}$ should not be more than $1 / 3$ of the distance between the current electrodes A B. A four-point symmetrical installation in which equal distances $\mathrm{AM}=\mathrm{MN}=\mathrm{AB}$ is called $\mathrm{a}$ Venner installation.

The resistivity of rocks depends on the resistance of the minerals composing them, the mineralization of the water filling the pores, porosity, humidity, texture of the studied rock, and other factors. The value of UES has a high information capacity that displays the humidity, the degree of salinity and other properties of rocks.

The distance of the electrodes and the relative position of the current and measuring electrodes changes the depth of current penetration into the earth. If you increase the distance between the current electrodes, without changing the position of the center of the installation, the depth of current penetration into the ground increases and, accordingly, the value of the rc begins to be influenced by rocks lying at a greater depth. In this case, periodic measurements of the UES with an increase in the distance between the current electrodes at a constant position of its center allow us to differentially study the geological section as a function of depth. This method of studying UES is called the method of vertical electric sounding (VEZ) (Fig. 2).
A

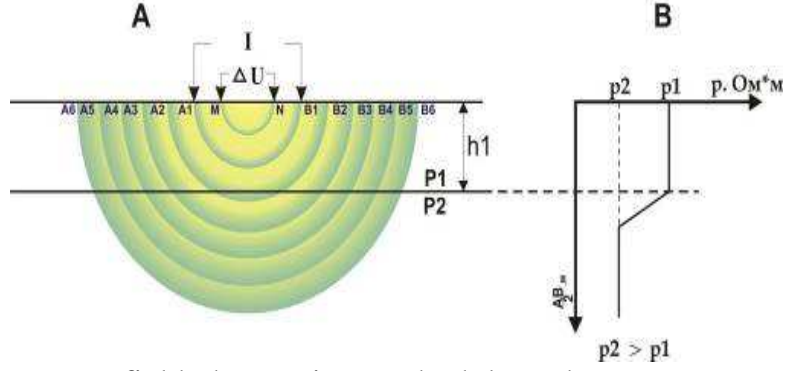

Fig. 2. Vertical electric sounding method

$$
\rho=\mathrm{K}^{*}(\Delta \mathrm{U} / \mathrm{I}),
$$

where $\rho$-electrical resistivity;

$\Delta \mathrm{U}$ - potential difference, $\mathrm{B}$;

I - electric current, A;

$\mathrm{K}$ - coefficient that takes into account the geometry of the placement of the electrodes.

The result of the work by the VEZ method is the construction of curve $p=f(A B / 2)$ at each observation picket, and eventually - curve $p=f(h)$, since the depth of the research $h$ depends on the size of the spacing of the supply electrodes AB. For engineering or geological work in sand-clay sections typical of the Stavropol Territory, the depth of the study $h$ is assumed to be equal to the value of the half-spacing of the feed electrodes $(\mathrm{AB} / 2)$, multiplied by the depth coefficient $\mathrm{Kgl}$, equal to 0.7 , which depends on the lithology of the section under study and can be specified for each specific area of work:

$$
\mathrm{h} \approx 0.7 \times \mathrm{AB} / 2
$$

The method of symmetric electric profiling.

For conditions when the relative position of the current and measuring electrodes does not change, while the installation moves along a certain direction from measurement to measurement, this method of studying the UES is called electroprofiling.

Electroprofiling and probing can be performed in the form of route or area surveys. The size of the research 
object determines the shape and density of the network. The results of the route survey are usually expressed in the form of graphs of changes in electrical resistance along the observation profile.

The main advantage of electric profiling is the simplicity of observations and high productivity of field work. The disadvantage is the relatively low information content due to the fact that the measurements are made at almost the same depth of penetration of the electric current, i.e. at a constant depth of research.

Examples of practical use of electrical exploration in agricultural fields clearly show the close relationship of the specific electrical resistance with the position of the UGV, the ability to assess the overall reclamation situation of the studied area of work using isoom maps [2].

In most methods of onshore and downhole electrical exploration, electric current is introduced into the thickness of the studied rocks by contact (galvanic) means using current electrodes. To control the soilreclamation situation, studies are carried out with a small depth, current and measuring electrodes are metal rods with a diameter of $10-15 \mathrm{~mm}$ pointed at one end, the length of these electrodes is from 20 to $40 \mathrm{~cm} \mathrm{[3].}$

Current electrodes are usually made of steel, relatively high currents pass through them, so in the case of their oxidation and the occurrence of polarization currents when they are immersed in the ground, the influence of such currents can be ignored. In the MR measuring electrodes, the recorded voltages are much lower than in the current electrodes, so the polarization currents cannot be neglected, in this case it is preferable to use copper or brass measuring electrodes, the polarization of which is significantly lower than steel. The greatest reduction in the influence of electrode potentials, especially those that vary greatly in the uppermost part of the section, could be achieved with the use of lead electrodes, but they are not suitable for ground work due to their low mechanical strength. A compromise solution is the use of MM receiving electrodes made of steel or brass, served with lead at the point of contact of the electrode with the ground [4].

\section{Results and Discussion}

One of the variants of the electro-logging probe developed and manufactured in NCFU is a fourelectrode design, in which each of the electrodes is attached to a rubber washer $5 \mathrm{~mm}$ thick and 2-3 $\mathrm{mm}$ in diameter less than the diameter of the well. The washers are mounted on a screw-shaped rod made of brass. The probe is immersed in the well to a predetermined depth under the action of a mechanical force compressing the rubber washers, so that the electrodes are tightly pressed against the wall of the well.

The results of the practical application of soilreclamation geophysics in the conditions of the Stavropol Territory are presented on the example of the research carried out at the kolkhoz. Gorky, Trunovsky district.
For an agricultural enterprise or farmer, choosing the optimal work area from several options is the most important from the point of view of competitiveness.

Figure 3 shows the solution of such a problem with the help of areal electrometric work by the VEZ method. There are three separate fields with an area of about 100 hectares each. In field No. 1, low-resistance rocks that characterize the aquifer are not found at all at a depth of up to $3.5 \mathrm{~m}$. In field No. 3 , they are observed only at a depth of more than $1.75 \mathrm{~m}$. In field No. 2, low-resistance rocks occupy a third of the area at a depth of up to $1 \mathrm{~m}$ and almost the entire map area at a depth of up to $3.5 \mathrm{~m}$. Verification drilling in the volume of 17 wells showed a domed rise in the ground water level from a depth of 2.2 $\mathrm{m}$ to $60 \mathrm{~cm}$. The reason is a pipe break in the water supply system to the sprinkler system.

Thus, according to the results of areal geophysical works, field No. 1 is the most favorable in terms of land reclamation, field No. 2 is the most unfavorable, and field No. 3 occupies an intermediate position.

Due to the fact that the electrical resistivity of rocks depends on many factors, primarily on the humidity and salinity of soils, additional information about the properties of rocks in the aeration zone can be very useful when processing and interpreting electrometric data, such as the depth of the groundwater level in wells - humidity $\mathrm{W}$ and salinity of rocks $\mathrm{C}$, determined in laboratory conditions from rock samples, mineralization of groundwater, determined from water samples in wells. In many cases, the information obtained during the analysis of vegetation in the field under study can be useful.
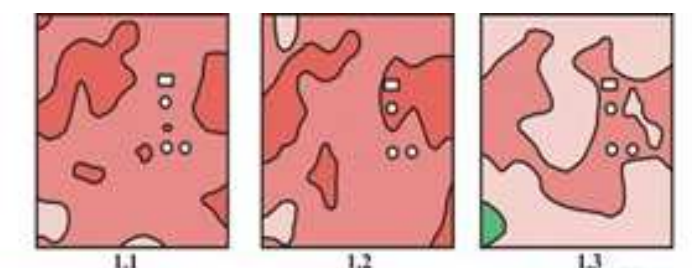

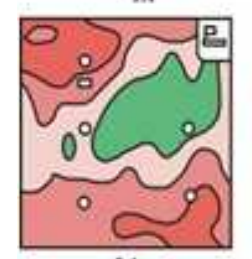

2.1

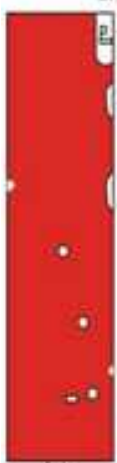

3.1

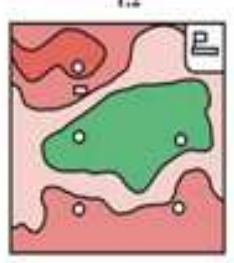

2.2

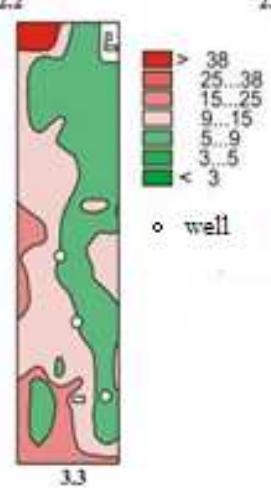

Fig. 3. Isoom maps in fields 1, 2, 3 of the kolkhoz named Gorky 
Research depth:

0 - $1 \mathrm{~m}(1.1,2.1,3.1) ; 0$ - $1.75 \mathrm{~m}(1.2,2.2,3.2)$;

$0-3.5 \mathrm{~m}(1.3,2.3,3.3)$

This, first of all, applies to cultivated crops: their condition (the density of seedlings, the height and volume of the stem, the mass of the root system and leaves, their color and other parameters) largely depends on the depth of the UGV, and therefore on the reclamation situation in the studied field area. The appearance of reed outlets on the field (Fig. 45 a) indicates a clearly unfavorable reclamation situation, an abnormal rise of groundwater to the daytime surface, and possibly the presence of flowing water at a shallow depth. The presence of salt-loving plants on the field can tell about the increased salinity of the soil section.

Electrometric work on the operational assessment of the reclamation state of soils, especially at the stage of developing the methodology, should be carried out in conjunction with standard reclamation work. Their methodology was developed decades ago, but their joint implementation with electrometric work requires a certain consistency. The accompanying field geophysical work should include such types of work as topographic, drilling, borehole measurements of the depth of the UGV, water sampling to study their mineralization, soil sampling to analyze their humidity, salinity, and mechanical composition.

The depth of occurrence of UGV, determined on the studied profile from well data, can provide additional information about the influence of a particular factor on the reclamation state of agricultural land. Thus, the calm behavior of the groundwater mirror with an abnormal increase in isooms in the vertical section (Fig. 4) indicates the predominant influence of saline rocks on this section of the profile.

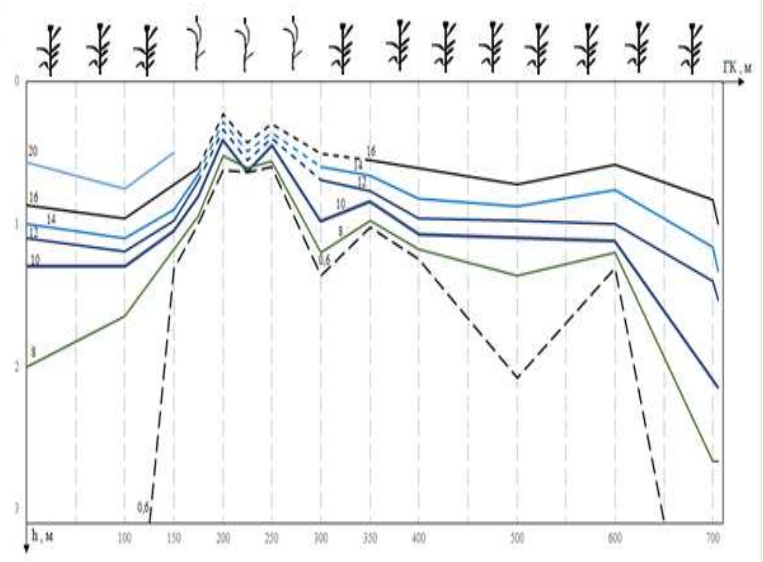

Fig. 4. Isoom sections showing areas of deterioration of the reclamation situation

Of particular interest is the comparison of the depth of occurrence of UGV and the maximum moisture content of rocks. Theoretically, these values should coincide. However, in practice, the depth of maximum humidity, as a rule, exceeds the depth of the occurrence of UGV. This ratio of these values can be explained by the discrepancy between the depth of the UGV measured in the well and the true position of the groundwater that they occupied before drilling. On the one hand, this can lead to an important conclusion about the possible influence of increased pressure in the aquifer, which decreases to atmospheric pressure as a result of drilling.

A quantitative assessment of the areal distribution of soils by the depth of rocks with different UES gradations can be presented in the form of histograms, an example of which is shown in Figure 5.

The VEZ method allows us to solve this problem without fundamentally changing the recording equipment and working methods, only longer distances of the supply lines and a corresponding increase in the power of current sources are required [5].

\section{Conclusion}
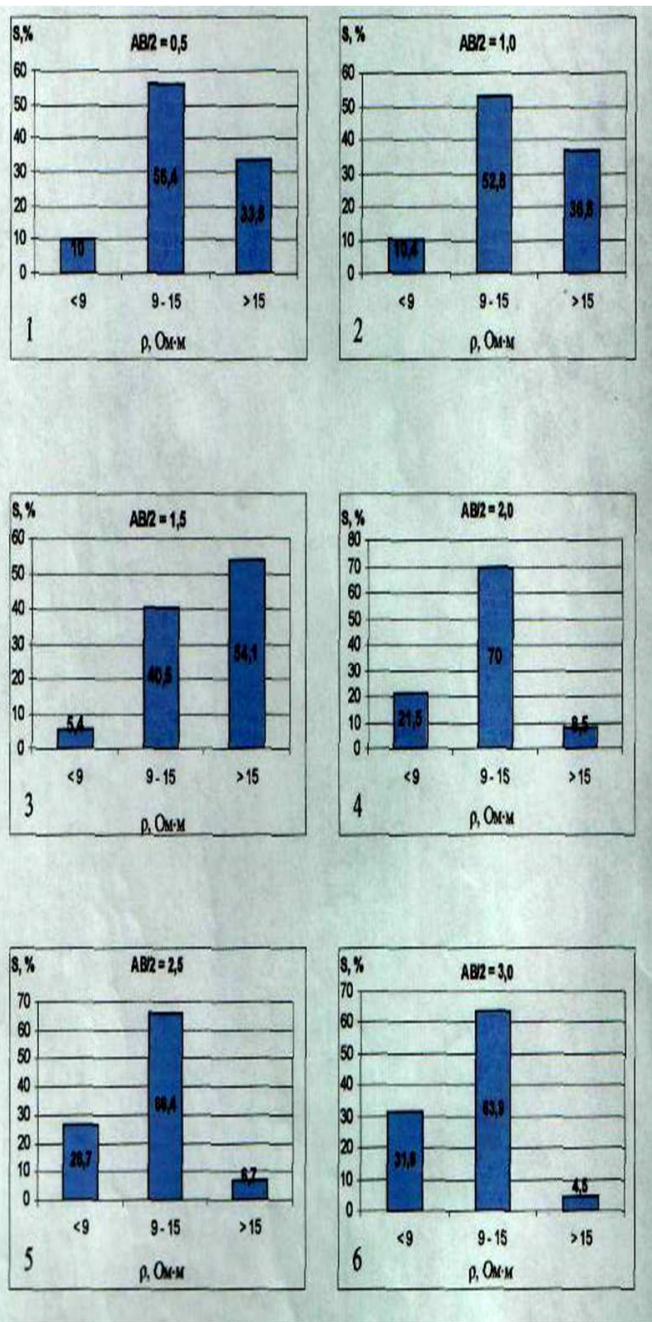

Fig. 5. Histograms of the areal distribution of soils using a three-point system for assessing the reclamation state

The conducted studies have shown the effectiveness of the electrometric method of vertical electrical sounding, which allows, based on surface observations with a minimum amount of control drilling and analytical work, to obtain operational information about changes in the area and depth of such an important parameter for assessing the reclamation state of soils as their specific 
electrical resistance, depending on humidity and salinity, that is, on those parameters that most determine the reclamation situation in the studied field. The VEZ method, in addition to the available information about waterlogged and saline wetlands observed on the earth's surface by traditional methods, allows us to obtain information about hidden unfavorable zones: about changes in their configuration in area and depth, about their mutual location relative to other soil zones.

The depth of the study based on the daytime surface

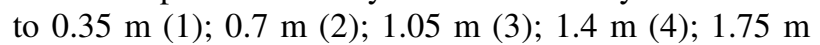
(5); $2.1 \mathrm{~m} \mathrm{(6);} \mathrm{bad} \mathrm{-} \mathrm{p} \mathrm{less} \mathrm{than} 9$ ohms*m, satisfactory p from 9 to 15 ohms*m, good - p more than 15 ohms*m.

Therefore, the introduction of electrometric methods in the practice of soil reclamation research will allow a more objective assessment of the size and position of waterlogged and saline lands in the studied areas, which is necessary for the development of effective measures to combat this environmental disaster.

The work was carried out using the Center for Collective Use of the North Caucasus Federal University with financial support from the Ministry of Education and Science of Russia, unique project identifier RF ---- 2296.61321X0029 (agreement No. 075-15-2021-687).

\section{References}

1. Y. Yakubovsky. Elektrorazvedka (Moscow: Nedra, 1973)

2. E. Kuznetsechenkov, A-G. Kerimov, E. Sokolenko, V. Kramarenko. Methods of engineering geophysics in the South of Russia. Monograph (Stavropol: Publishing House of the NCFU, 2018)

3. A. Ogilvi, Fundamentals of Engineering Geophysics (Moscow: Nedra, 1990)

4. F. Zaidelman. Soils of wetland landscapes formation, agroecology and melioration (Moscow: MGU, 1998)

5. V. Kolesnikov. Fundamentals of Interpretation of Electrical Soundings. (Moscow: Scientific world, 2007) 